\title{
Futures Narratives, Possible Worlds, Big Stories: Causal Layered Analysis and the Problems of Youth
}

\author{
by Cate Watson \\ University of Stirling
}

\author{
Sociological Research Online 14(5)20 \\ <http://www. socresonline.org.uk/14/5/20.html> \\ doi:10.5153/sro. 1969
}

Received: 8 Jan 2009 Accepted: 9 Aug 2009 Published: 30 Nov 2009

\begin{abstract}
Narratives of the future can be seen as a form of colonialisation, structuring fields of discourse, in a process which Johan Galtung (cited in Andersson, 2006) refers to as 'chronological imperialism'. However, futures narratives can also be used to disrupt these attempts at colonialisation through surfacing problematic assumptions in order to explore alternative scenarios. In this paper I first consider modal narratives and possible worlds and their relevance to the social sciences. I then discuss Sohail Inayatullah's 'Causal Layered Analysis' (CLA) - a narrative technique for constructing past and present and imagining the future. CLA draws on a 'poststructural toolbox' to examine problematic issues using a process which focuses on four levels of analysis: litany (the official public description of the issue); social science analysis (which attempts to articulate causal variables); discourse analysis or prevailing worldview; and myth/metaphor analysis. The aim is to disrupt current discourses which have become sedimented into practice and so open up space for the construction of alternative scenarios. In the third part I demonstrate how this approach can be used to examine 'big issues' taking as my example the current preoccupation with troubled and troublesome youth.
\end{abstract}

\section{Keywords: Causal Layered Analysis, Childhood, Ethical Spectacle, Family, Futures Narrative, Futurology, Risk Factors, Scenario, Youth, Youth Crime}

\section{Introduction}

1.1 Charles Tilly distrusts stories - or at least what he refers to as 'standard stories' - by which he means 'tales, fables or narratives...the sequential, explanatory accounts of self-motivated human action', arguing that 'sociology's strongest insights do not take the form of stories and often undermine the stories people tell' (1999:257). But perhaps he protests too much. It seems, rather, that what Tilly dislikes are not stories per se but the acceptance of stories at face value or the construction of research narratives which work uncritically within the discourses they should aim to confront, because it seems that Tilly quite approves of 'superior stories', the writing of which requires an inclination to reflexivity and an examination of both the construction of stories and the discourses which produce them. Tilly, of course, was concerned with the past, but not only for the 'moral, political, psychic, and aesthetic value of knowing that we now live in only one of many possible worlds' but because history 'provides a key to the present and a guide to the future' (1990:685). So he might well endorse 'causal layered analysis' (CLA) (Inayatullah, 1998a, 2004), as a conceptual toolbox for the construction of superior stories of possible worlds.

1.2 'Narratology and futurology' says James Phelan (2006:85), 'make strange bedfellows. The default tense for narrative is past, and narratologists, like detectives, typically work retrospectively...Futurology, by contrast, takes the future as its default tense...'. You can see his point, but time and narrative are inextricable and there is an undeniable link between history and futurology, so that possible futures, what Jouvenel (1967) calls futuribles ${ }^{[1]}$, 'should be thought of as those descendents from the present state that now seem to us possible' (Jouvenel, 1967: 19).

1.3 Indeed, it is narrative which gifts us the experience of time, thereby enabling us to conceive of an illusory point-like present which is in fact 'always already past and always already still to happen' (McQuillan, 2000:15), but narrative is also bound up with space as a practiced place (de Certeau,1998), and it is perhaps useful to imagine the future as narrative space occupiable by a plurality of possible worlds. Yet, in a review of Ossip Flechtheim's book History and Futurology, published in 1966 (Flechtheim 
was the originator of the term futurology), John $\mathrm{H}$. Herz writes, Throughout history the future used to be "open". Now...even the future is no longer what it used to be' (1966:1020). Instead the future has become an invisible war zone in which a battle rages for its soul. The weapons in this fight, this attempt to colonialise the future, are in fact the big ideological narratives constructed in an attempt to impose, as Johan Galtung puts it (cited in Andersson, 2006), a chronological imperialism, to plant a flag and claim it before the rest of us even get there. But the counter weapons are also narratives, perhaps smaller ones, enabling skirmishes into the future - counter-narratives to disrupt hegemonic discourses - and as Gilles Deleuze (1995:178) says when confronting these forces, 'it's not a question of worrying or hoping for the best, but of finding new weapons'.

1.4 The purpose of this paper then is to examine narrative as a guerrilla tactic in this battle for the future. I first consider futures narratives and possible worlds and their relevance to the social sciences, before moving on to discuss causal layered analysis as a narrative technique for constructing past and present and imagining the future (Inayatullah, 1998a, 2004). Briefly, CLA uses a 'poststructural toolbox' to examine problems using a process which focuses on four levels of analysis: litany (the public or official description of the issue); systemic causes (attributions of causal variables); discourse analysis or prevailing worldview; and myth/metaphor analysis. CLA is not about forecasting or prediction but about storytelling, a means for the construction and exploration of possible worlds. In this paper I use CLA to examine current constructions of 'youth', as in 'youth in crisis' and 'at risk', in order to open up space for the construction of scenarios which disrupt current discourses. It will be left to the reader to assess whether, and to what extent, the approach succeeds in generating Tilly's 'superior stories'.

\section{Futures narratives, possible worlds}

2.1 Futurology, the scientific study of the future, is a project of high modernism in which the future is claimed not as 'a product of fantasy but a field of reason' (Andersson, 2006:280). Futurology reached its apotheosis in the latter part of the 20th century, rising in response to the need for national and economic security in the era of the Cold War as a science capable of predicting and so controlling the future. It is a term, however, that has apparently fallen out of favour even with its practitioners who nowadays prefer tags less likely to convey a sense of the future as monolithic. Perhaps in part this is because the scientific pretensions of futurology have been pricked by enjoyably inaccurate predictions like personal jet packs ${ }^{[2]}$ but part of the failure of futurology, as technology of control, arises precisely from its leanings towards utopianism as social engineering. Polak (1961:21) sums up the utopian paradox neatly: 'Every utopian ideal would, if it could be realized (which fortunately it cannot), cause the most incredible disasters. The true utopia is then in fact dis-utopia, since virtue and goodness lead inevitably to social collapse ${ }^{[3]}$. In the narrative of futurology, the trickster plays a central role subverting our rationally planned extensions and extrapolations, utopian and eschatological alike - just think, 'No more boom and bust ${ }^{14]}$. Futurology then also came to represent a crisis of modernity, embodying 'both an extreme idea of social engineering - the idea of engineering the future in the name of the common good - and a fundamental critique of the objectivity and technocracy at the basis of social planning' (Andersson, 2006: 279). From this crisis 'critical futures studies' arose, 'a counter hegemonic discourse...tied to deconstructing dominant forms of knowledge and creating dissenting futures' (Inayatullah, 1998b:382).

2.2 Attempts to imagine the future often depend on the production of scenarios, developed in response to questions of the 'what if?' kind. Walton (2008:149) cites Godet (2001) who distinguishes between 'proactive innovative scenarios (aimed at illuminating a future that otherwise might not happen) and what he terms preactive scenarios that allow one to prepare for anticipated changes in the future environment' (original emphasis). Scenarios, Booth et al (2008) argue, are intrinsically modal in nature. Modal narratives are concerned with necessity and possibility and their converses, contingency and impossibility. The main role of modal narratives, the authors suggest, 'is to draw attention to differences between the actual world and various possible worlds, and not to actualize the possible' but rather 'to subvert belief in the real, or what is accepted as real' (Booth et al, 2008: 7).

2.3 Our ideas about what is accepted as real are inevitably historically and culturally conditioned. To understand that, in Tilly's words 'we now live in only one of many possible worlds' (1990:685), it is illuminating to consider epistemologies and ontologies in other places, other times. I recently had cause to consult Ulisse Aldrovandi's Ornithologiae published in 1610. This ornithology includes Vespertilio, the bat, and engravings of Harpies sit alongside ostriches and parrots. It was quite astonishing to be brought face to face with this pre-Linnaean world so used are we now to the idea of 'natural classification'. The epistemology that underpins Aldrovandi's classification evinces a radically different world from the one we now live in (Watson, 2008).

2.4 Doležel (1998) also makes the point that possible worlds are human constructs: 'Contemporary thinking about possible worlds is not metaphysical. Possible worlds do not await discovery in some remote or transcendent depository, they are constructed by the creative activities of human minds and hands' (Doležel 1998: 14); and he goes on: 'Viewing possible worlds as human constructs brings the concept down from the metaphysical pedestal and makes it a potential tool of empirical theorizing. For various cognitive aims various kinds of possible worlds can be stipulated'. Doležel sets out a typology of possible worlds, each associated with its 'cognitive aim' including possible worlds of:

- logical semantics $\rightarrow$ interpretive models

- philosophy $\rightarrow$ coherent cosmologies

- religion $\rightarrow$ cosmological narratives

- natural science $\rightarrow$ alternative designs of the universe

- historiography $\rightarrow$ counterfactual scenarios

- action theory $\rightarrow$ different possible courses in the life history

- fiction $\rightarrow$ artefacts produced by aesthetic activities 
2.5 A scenario, in the sense in which it is used in futures studies in general and CLA in particular, can be said to combine elements of many if not all of Doležel's possible worlds but perhaps particularly historiography and fiction. A historical counterfactual is constructed along the lines of 'what would have happened if....'. Its starting point is therefore an actual world state of affairs or event. A fictional world is 'a small possible world shaped by specific global constraints and containing a finite number of characters who are compossible' (Doležel, 1998: 20) i.e. can co-exist.

2.6 In futures studies possible worlds are similarly shaped by specific global constraints: 'a future state of affairs enters into the class of "futuribles" only if its mode of production from the present state of affairs is plausible and imaginable' (Jouvenel, 1967:18). However, Booth et al (2008) question the criterion of plausibility, or at least qualify it, arguing that 'doxastic-axiological uses of modal narratives' (i.e. those concerned with highlighting gaps or contradictions in belief or value systems) demand a sense of 'cognitive estrangement' precisely in order to subvert what is currently accepted, yet this estrangement must operate within a liminal zone, whereby knowledge is partial and we strive to understand something now just within, and formerly outside, our cognitive horizons'. This tension between cognitive estrangement and plausibility constitutes the narrative space within which critical futures studies are situated.

2.7 In the next section I set out CLA in more detail and then apply it to a consideration of the currently constructed social problem of 'youth', in order to explore what the method may have to offer as a subversive tactic in the futures field.

\section{Causal Layered Analysis as method}

3.1 As mentioned earlier, CLA adopts four levels of analysis in the construction of scenarios. The first level, the level of the litany is fairly straightforward - what gets reported in the headline press and the media generally. Level two, systemic causes, approximates to Tilly's 'standard stories' i.e. how do standard stories interpret events, producing cause and effect? Inayatullah (2004:17) suggests this level is that of the newspaper editorial, policy institute or the 'not quite academic' press. It is the construction of plausible explanation that results from putting the characters in motion and tracing the accumulated effects of their actions to some interesting outcome' (Tilly, 1999:257). Level three, discourse, takes the process further, in effect doing what Tilly urges when he speaks of the need to confront storytelling:

Hence, a three-faced problem ${ }^{[5]}$ : how to cut through the limits set by prevalent stories on the explanation of social processes, how to convey valid explanations of social processes when audiences customarily wrap their own explanations in storytelling, and how to describe and explain the creation, transformation, and effects of existing standard stories. (Tilly, 1999: 257)

3.2 Level three, 'tunnel[s] under standard stories' (Tilly, 1999: 266) analysing the discourses within which standard stories are constructed. Level four, myth or metaphor, burrows into the cultural psyche to examine the enduring stories that shape understandings.

3.3 The four levels can be visualised as tapping into a number of dimensions along axes of time and space. Space is conceptualised in terms of depth (I have already used the metaphors of tunnelling and burrowing). Along the time axis the litany relates to the here and now, while myth and metaphor are more enduring, representing the timescale of macrohistory. By analysing the 'problem' from these different perspectives the approach aims to gain insight into the future, 'not [as] forecasts but images of the possible that critique the present' (Inayatullah, 2004:14). The aim is to produce different ways of knowing, to disrupt received wisdoms and the appeal to 'common sense', to see what happens when we do this and start to construct other possible worlds.

\section{The CLA toolbox}

4.1 Inayatullah's 'poststructural futures toolbox' consists of five concepts:

- deconstruction

- genealogy

- distance

- alternative pasts and futures

- reordering knowledge

4.2 Each tool is associated with a number of questions and, says Inayatullah, may be applied at any level, though some tools lend themselves more readily to particular levels than others. Deconstruction asks questions such as: which future is privileged? Which assumptions of the future are made possible? Genealogy asks: which discourses have been victorious in constituting the present? What might be the genealogies of the future? Distance asks: which scenarios make the present remarkable? Make it unfamiliar? Alternative pasts and presents asks which interpretation of the past is valorised? What histories make the present problematic? Which vision of the future is used to maintain the present? Finally, Reordering knowledge asks: How does the ordering of knowledge differ across civilisation, gender and episteme? Who or what is othered? (Inayatullah, 2004:13, 14).

4.3 CLA has been used to address issues as diverse as maternity leave (Morrow, 2007), racism, poverty, sustainability, and the future of the aviation industry (see Inayatullah, 2004 and case studies therein). It is particularly suited to examining what Rittel and Webber (1973) refer to as 'wicked problems', that is big problems that have shaken 'the traditional faith in a guaranteed progress':

As distinguished from problems in the natural sciences, which are definable and separable and may have solutions that are findable, the problems of governmental planning - and especially those of social or policy planning - are ill-defined; and they rely upon elusive 
political judgement for resolution. (Not 'solution'. Social problems are never solved. At best

they are only re-solved - over and over again.) (Rittel and Webber, 1973: 160)

In the approach I have adopted in this paper the analysis has been used to prompt a number of 'scenario points' which are intended to disrupt current understandings and the appeal to commonsense through generating visualisations of different worlds.

\section{Causal Layered Analysis applied to the Problems of Youth}

\section{Level One: The Litany}

5.1 The litany surrounding the 'problem of youth' is fairly straightforward - 'Violent youth crime up a third', exclaims the Daily Telegraph, (20.01.08). The simultaneously authoritative though rather meaningless figures 'up from 17,590 to 24,102' are given narrative force by means of a quote from Helen Newlove, widow of Garry Newlove, 'father of three beaten to death as he stood up to a street gang', who says, 'for too long young thugs have got away with a slap on the wrist'. Similar headlining stories can be found in every UK newspaper on almost any day of the year: 'Figures reveal horrifying picture of our yob culture' (Daily Express, 14.07.09); 'Youth crime soars in last five years as gang culture takes a grip' (Daily Mail, 10.11.08); 'Shocking pictures of neds ${ }^{[6]}$ brandishing weapons and drugs on YouTube' (Daily Record, 05.08.08). The BBC's 'Breakfast' Programme (27.11.08) carried an item about 'Wheelie Bin Fires', as a current scourge perpetrated by youth, and paraded two elderly 'Wheelie Bin Fire Victims' rescued from their flat after it was set alight by a flaming wheelie bin. But not only do the young present a threat to us adults they are also hell bent on 'slashing and shooting' each other (The Sun, 30.05.08), with figures for teenage murders reaching an 'all time high' in 2008 ( The Times, 15.09.08). It is perhaps not surprising then, given this unremitting diet, that in a survey carried out by the children's charity Barnardo's.

- just under half $(49 \%)$ of people believe that children are increasingly a danger to each other and adults

- $43 \%$ agree something has to be done to protect us from children

- $45 \%$ think that children are feral in the way they behave.

Despite attempts to reassure us - The Barnardo's report [2008:4] states soberly, that 'most children and young people are not troublesome - they attend school, take part in activities and a significant number are volunteers', fear of the young is rampant.

5.2 But the young can also be portrayed as victims. The Socialist Review (June 2005) highlights the pressures on 'young people' (not, note 'youth') from advertisers: 'Young people, struggling to find an identity, can be easy prey for the corporate vultures. They are sold images of independence, acceptance, success and power through consumption'. Relatedly, Gidley (2005: 20-21) warns that 'we are seeing an unprecedented fragmentation of the social glue without which young people are rudderless in their social orientation' and she refers to the colonization of imagination' in which:

the imaginations of children and youth has changed from the nourishment of oral folk and fairy tales to the poisoning of interactive electronic nightmares. Since the advent of TV, and video game parlors, followed by the use of computer games... Sestern children and youth have been consistently and exponentially exposed to violent images...Is it surprising then that over the past decade in particular, symptoms have appeared among young people...of ever increasing violence and suicide.

5.3 This argument concerning the impact of exposure to violent images is frequently appealed to, yet the binary constituted by : 'oral folk and fairy tale' (nourishing) / 'interactive electronic nightmare' (poison) can be readily overturned ${ }^{[7]}$. After all, many fairy tales are rather $\operatorname{grim}(\mathrm{m})$ and their purpose may not necessarily be benign.

5.4 The litany concerning youth goes along with other familiar news stories concerning the breakdown of the nuclear family, child abuse and the growth of the 'feral' underclass.

\section{Scenario point:}

I pick up a discarded copy of the Metro (27.11.08) on the train. The headline on page 8 says, 'Upbringing "could have turned Baby $\mathrm{P}^{[8]}$ feral"'. The article goes on: 'Baby $\mathrm{P}$ might have turned into a feral parasitic yob had he survived, the head of Barnardo's said yesterday' - and then, of course, we would have locked him up. Thereby making an uncomfortable connection between two litanies we prefer to keep separate. ${ }^{[9]}$

5.5 The headlines generate feelings of helplessness, apathy and calls for government to 'do something'. This has resonance with Virilio's (2007: 18) concept of 'fear management' in which, he says, our emotions are manipulated by 'the Ministry of Fear - run by the movie industry and mass media as integral parts of the audiovisual continuum now replacing the public space of our lives'. This produces, Acland (1995) says, a 'felt crisis' (original emphasis), part of an 'affective epidemic'. 'How' he goes on, 'is the "truth" of this felt crisis enacted and enforced and to what ends, to whose benefit, to whose disadvantage? How does it become a site around which various political agendas are organized?'.

5.6 This is part of 'the project of hegemony through crisis' (Acland, 1995:41). In effect 'youth' as social identity becomes, in Laclau and Mouffe's (1985) terms an empty signifier, drained of meaning - a repository for our fears - forming a constitutive outside to the hegemonic discourse, producing social antagonism. Social antagonism 'simplifies the social space by establishing a dichotomous division of society into two camps, and thereby contributes to the stabilization of the social order' (Torfing, 1999:51). The media driven 
discourse of 'Wasted youth' becomes a public spectacle (Katz, 2008), 'creating a broad and open-ended terrain for intervention, both material and spectacular. Through this intervention the social order is produced, reproduced, maintained and given meaning' (Katz, 2008: 14). But in this case, what resonates is not simply 'social order' in the sense of orderliness, and the apparently (but only apparently) paradoxical idea that disorder contributes to the production of order, but the 'natural' order of life, decay and death too. For, while 'youth is Other to the order of the adult world, it is also an object of intense interest, desire, even longing, for the culture as a whole' (Acland, 1995:19) - and a constant reminder of our loss.

\section{Level two: The systemic level}

5.7 How government responds to the crisis of youth depends on the way in which the problem is framed, and this is shaped by the kinds of cause and effect analyses which are the focus of the systemic level of $\mathrm{CLA}$. The systemic level examines the explanations and solutions for this apparent social meltdown as propounded in the 'not quite academic' press, as Inayatullah (2004) puts it: editorials in the broadsheets, policy documents, serious weeklies and so on. In contrast to the often rabid responses of the 'string 'em up' kind evident in some sections of the popular press and increasingly on newspaper internet forums, blogs etc, here we get more serious comment (though still along a continuum of sophistication), generating a narrative which seeks to explain, but which remains within the discourse that constitutes 'youth' as a problem. This, it can be argued, relates to Tilly's 'standard stories'.

5.8 A short and fairly random search produces pieces such as: The FirstPost's 'Blame the killer kids on the middle classes' which claims that, 'British society, while getting richer, is becoming ever more primitive and savage' and says, 'The welfare state and the progressive attitudes of the 1960s unpicked the stitching that held the British working class together during two World Wars and the great depression of the 1930s. 'This is the underbelly of the utopian ideal of 'cradle to grave' care exposed - a 'feral' class created by the very policies and ideals that sought to address social inequalities.

5.9 Two reports in the Joseph Rowntree Foundation's 'Social evils' series place the blame on individualism, consumerism (Thrake, 2008) and the 'absence of society' (Bauman, 2008). This is the more scholarly end of the spectrum, but a more pervasive locus of blame is the family. Iain Duncan Smith's policy think tank, the Centre for Social Justice says:

in order to avoid tackling the symptom and not the cause, the spotlight has to be turned on the family. Most British families function well, nurturing children to become law-abiding citizens. Broken families, however, are often the places where the seeds are sown for future criminal activity. (Centre for Social Justice, undated: 5)

5.10 In the Economist (10.04.08) Nicholas Phillips, Lord Chief Justice, is quoted as saying:

The fundamental point is that children who are brought up by loving parents who are themselves responsible don't very often commit criminal offences...If you analyse those who end up in young-offender institutions and look at their backgrounds, you'll find that they aren't coming from solid family backgrounds and some of them haven't effective parents at all.

5.11 And in the vacuum created by the meltdown of the nuclear family a new kind of tribal grouping is being created, as elsewhere in the article Dawayne Gordon, explains, 'People are joining gangs to find belonging and protection. The family model's got mucked up'. An analysis that prompts a re-evaluation of 'family'.

\footnotetext{
Scenario point:

Three alternative conceptions of 'family' :

1. Stephenson's (2001) study of street children in Moscow challenges the 'paradigm of disaffiliation' which 'assumes or even insists, that they live in disorganised, illegal misery'. Instead, the children attempt to 'reconstruct the lost families and create self-supportive networks' (Stephenson, 2001: 533). One such network is the 'Arbat system', a self-regulating community of youth subcultures with a 'complex social structure of extensive networks with a system of mutual obligations and trusts...sustained by a set of quasi-familial relationships' (Stephenson, 2001: 538).

2. "History also casts light on who constitutes "family". Despite current emphasis on legal or biological ties, families in eighteenth century England and North America were made up of whomever resided in the household, and it is notable that this is the current first definition in the Concise Oxford Dictionary. This usually included non-related individuals who might be boarders, distantly related family members and apprentices, while biological kin such as children often resided in other households and were regarded as members of those families'. Private spaces for parents and children, whom we today regard as the legitimate family, were not considered important; houses being open spaces for everyone in the household.' (Pryor, 2006:7)

3. In Huxley's Brave New World babies are grown in vitro in hatcheries and brought up in conditioning centres. They are subjected to a chemically controlled development designed to fit them into a caste system of alphas to epsilons. The narrator explains that before this process was perfected: 'The world was full of fathers, therefore full of misery; full of mothers - therefore of every kind of perversion from sadism to chastity; full of brothers, sisters, uncles, aunts - full of madness and suicide. (Huxley, 2004/1932:33).
}

\section{Responses}

6.1 While the litany creates the moral panic as the narrative space within which government is called upon 
to act, policy is informed by constructions of cause and effect, conceptualised within the discursive and political milieux, which emerge at the systemic level. In an influential report Farrington (1996) identifies major risk factors for youth crime as:

- low income and poor housing

- living in deteriorated inner city areas

- a high degree of impulsiveness and hyperactivity

- low intelligence and low school attainment

- poor parental supervision and harsh and erratic discipline

- parental conflict and broken families

6.2 The analysis of risk and 'risk-focused prevention' has formed a key part of government responses since the 1990s (Armstrong, 2004). But Walters and Woodward (2007: 6) argue that 'risk', and its management, constitutes a discourse in which the identification of risk groups becomes wedded to processes of prediction and measurement' (mobilised around certain desired or preferred adult futures). The discourse of risk therefore constitutes a form of colonialisation of the future.

6.3 Responses to these risk factors are informed by 'an ensemble of conservative and "middle-ground" ideologies...that have become increasingly popular within western democracies' and which focus on the individual, and the immediate social environment of the child, rather than the structures of society itself. This leads to anti-social behaviour strategies which are 'underpinned by stigmatizing and judgemental attitudes towards underprivileged parents and children' (Walters \& Woodward, 2007:6). So we get Asbos (anti social behaviour orders) which exclude individuals from their communities, and Parenting Orders [10], intended to make feckless parents take their responsibilities more seriously [11].

6.4 Policy therefore constructs parents and youth of the 'lower classes' as problems, while privileging 'the middle class' which 'makes rules the lower class must obey - in the schools, the courts and elsewhere' (Becker, 2003:247). Meanwhile, the troubled and troubling offspring of the affluent are able to construct themselves, in Lord Chief Justice Nicholas Phillips' terms, as coming from solid family backgrounds and so find ways to hide their deviance from the pervasive gaze of social control. Moreover, it is part of the normalising effect of discourse that development of this policy itself is seen as unproblematic, indeed it makes the appeal to 'commonsense' as a legitimising force.

\title{
Level Three: Discourses and world views
}

6.5 Deconstruction, in classic Derridaean terms, involves the overturning of binaries which poststructuralism suggests have a peculiarly invasive hold on western thought. The most obvious place to start in this context are the oppositions produced in juxtapositions of childhood/youth and adulthood. Jeffs and Smith (1999, citing Wyn \& White, 1997) present a list of these 'supposed contrasts':

\section{Youth : adult}

\author{
becoming : arrived \\ presocial self that will emerge under the right conditions : identity is fixed \\ powerless and vulnerable : powerful/strong \\ less responsible : responsible \\ dependent : independent \\ ignorant : knowledgeable \\ risky behaviours : considered behaviour \\ rebellious : conformist \\ reliant : autonomous
}

6.6 These are oppositions that we, as adults, use to construct youth as other, as lacking. Moreover, the authors point out the term 'youth' is almost always 'employed to signify discussion of a social problem or behaviour being portrayed in a negative light' (Jeffs \& Smith, 1999). Thus, the authors argue, there is 'an essentialism built around age like the equivalent discourses constructed around, for example, gender or race' (though in fact, 'youth as problem' is frequently conflated with issues attending both gender and race. Youth as in 'troubled youth' tends to be associated with maleness - and frequently blackness. The 'problem with girls' tends to be associated with teen pregnancy (never 'youth pregnancy'), eating disorders and the like.)

6.7 Yet, they go on, 'adulthood is no longer an identifiable destination' - not even necessarily a one-way ticket. Katz (2008) points up a trend, in the US at least, but which to a lesser extent perhaps can also be recognised in the UK, in which adulthood is increasingly being viewed as 'a transitory phase between modes of childhood': 'One of the prime lures of retirement replays the fantasy of childhood's freedom' (Katz, 2008: 13), and she quotes an advertisement for retirement with the tagline, 'we don't know when childhood ends but we know when it begins again'. 'These ideas', Katz writes, 'raise boundary issues'. Boundary issues are evident too in 'the popularity of youthful fashions for adults' which blur distinctions that once demarcated youth/adulthood - even the notorious 'hoodie', the very signifier of troubled youth, has now been appropriated by the fashion industry as 'asbo-chic' hits the cat walks (The Guardian (08.10.06) - and there has been a recent explosion in the growth of 'bodywork' to keep us looking forever young.

\section{Scenario point:}

'What's the matter with him?' whispered Lenina. Her eyes were wide with horror and amazement. 
'He's old, that's all,' Bernard answered as carelessly as he could. He too was startled; but he made an effort to seem unmoved.

'Old?' she repeated. 'But the Director's old; lots of people are old; they're not like that.'

That's because we don't allow them to be like that. We preserve them from diseases. We keep their internal secretions artificially balanced at a youthful equilibrium. We don't permit their magnesium-calcium ratio to fall below what it was at thirty. We give them transfusions of young blood. We keep their metabolism permanently stimulated. So, of course, they don't look like that. Partly,' he added, 'because most of them die long before they reach this old creature's age. Youth almost unimpaired till sixty, and then, crack! the end.'

Brave New World, Aldous Huxley (2004/1932:95)

6.8 At the same time, Katz also notes 'a growing predilection for adult-looking baby and children's clothes' - as evinced, for example in the marketing of 'high heels for babies' (marketed by 'Heelarious'). This spectacle is part of what Katz (2008) refers to as the commodification of child as ornament. But, there is also an echo here of earlier concepts of childhood. Ariès (1962, cited in Aitken, 2001) says that in mediaeval Europe the move from child to adult occurred early in life without an extended period of transition. Children were dressed as adults and expected to belong to the adult world from an early age. The move to construct a part of the life span as the biologically determined (i.e. 'natural') period of 'adolescence' in the 20th century followed on from the development of the 'modern family' in its private space in the nineteenth century and the institutionalisation, expansion and prolongation of education.

6.9 Aitken also discusses the growth of the 'gobal child', 'contrived from fluid capital processes' (Aitken, 2001: 122). In the global North, this child is constituted through 'growth of an ideological predilection for individuation' and 'increasing activity and power in the market' (Aitken, 2001: 123), giving rise to what both Thrake (2008) and Bauman (2008) refer to as the twin social evils of individualism and consumerism. 'In a world that is being colonised by mass-marketing and consumption' (Milestone, 2007:180), to be a 'flawed consumer' is to be socially excluded. Meanwhile, in the global South the child is seen to 'lack childhood' and to be the victim of exploitation in 'Third World Sweatshops' (producing the goods consumed by the child in the global North), denied education and the essential experiences of childhood. (A binary that is ripe for deconstruction).

6.10 From his analysis Aitken (2001) therefore identifies three major phases in the concept of childhood/youth in the western world. These are: indifference (child/youth as part of the collective life), difference (new forms of intimacy developed as the result of spatial changes in the family following industrialisation); and currently the death of childhood and adolescence in which he argues the distinction between adulthood and childhood may... have begun to lose its edge' (Aitken, 2001: 122). King (2007: 200) attributes this in part at least to the discourse of children's autonomy and 'rights to self-expression and participation in decisions'. But he also points out that since it is adults who construct this discourse surrounding children the adult/child boundary/binary remains, however ambiguously and inconsistently it is applied. This inconsistency becomes readily apparent when children/youths resist or breach the 'plural, permeable' and 'contested' boundaries and act in 'unchildlike ways' not sanctioned by adults (Aitken, 2001:126).

6.11 A genealogy of childhood/youth thus provides us with one of Charles Tilly's really big stories, in which large patterns of change are apparent, from which we could make huge comparisons, in great swirls of history - though this might result in dangerous oversimplifications. In any case, what we can say is that what we regard as essentially normal and natural in terms of the life span and the family is clearly not that, and this provides us with scope for imagining different ways of being.

\section{Scenario point:}

Scenario 1: The boundaries between childhood, youth and adulthood disappear leading to an end to segregated education - that is education segregated by age. No more secondary schools within which 'youth' is so routinely constructed as a problem. Instead 'Learning Supermarkets' for the consumption (Transfer) of Knowledge. Browse the shelves - on special offer today in the numeracy section 'buy one get one half price!' (If you can work it out).

Scenario 2: Following on from current moves to raise the school leaving age to 18 , legislation decrees that no-one is allowed to leave school at all unless they go on to further/higher education, get a job or train for a profession/trade. A (Dis?)Utopian vision that puts an end to the problem of the NEET ${ }^{[12]} \ldots$

\section{Level Four: Myth and metaphor}

6.12 In establishing futures studies as social science Ehliasson (2008) contrasts two key metaphors that shape thought in western society: Hobbes' society as social contract in which nasty, brutish (and short?) man must 'give up part of his freedom' and Durkheimian 'society as organism and self-regulating system' (Ehliasson, 2008: 491) concerned with achieving balance and equilibrium. The Hobbesian view is about self interest, the Durkheimian, common interest. Each metaphor produces differently framed analyses and 'solutions' to the wicked problems that beset us. The social contract version is about controlling man's baser instincts, the society as organism about reaching consensus, an idea that rests on trust. While oscillation within and between these two positions is evident in the litany surrounding youth and in the policy responses offered, at present the Hobbesian position predominates.

6.13 These two metaphors rest on deeper cultural myths surrounding narratives of inherent goodness/badness of 'man', and innocence/sinfulness of children that resonate in our collective consciousness. Children's natural savagery, unless checked by adults, is the theme of Lord of the Flies 
(Golding, 1954); and there is a chilling scene in Barbarella (Vadim, 1968) in which feral children release sharp-toothed clockwork dolls to attack Jane Fonda. Adults' fear and fetishisation of youth is also apparent in Logan's Run (Nolan \& Clayton Johnson, 1967), a future world in which the law requires that at the age of 21 (though this is upped to 30 in the 1976 film version) citizens must report to the 'sleepshop' for execution.

6.14 Fear of the young, and a belief in their inherent badness, leads to an ideology of punishment, an increase in surveillance of all kinds, and to the acceptance of responses such as the 'Mosquito' an 'ultrasonic youth deterrent' aimed at dispersal of groups of youth (hanging around on street corners) which, claims the manufacturer (Compound Security), is 'a completely benign non-physical deterrent system that has been specifically designed to annoy teenagers'.

6.15 Metaphors which attend youth specifically concern transition and development, thereby focusing on individual deficits in relation to desired adult future states. The modernist discourse of adolescence frames this transition in terms of turbulence - or, as Greville Stanley Hall characterised it, 'storm and stress'. These metaphors legitimise forms of control over youth, yet as Maira and Soep (2004:254) point out, the taken-for-granted notion of age-based transitions masks the role of the state in organizing social relations in capitalist society'. Currently, Kelly (2006: 23) argues, 'These [neoliberal] governmental ambitions would have as their ends modes of subjectivation that promise to produce the entrepreneurial self'. The metaphor of Youth as transition creates a discourse in which the emergence of this entrepreneurial self is itself jeopardised and at risk. This 'imagineering', as colonisation of the future, concerns the 'relations of power that shape personhood' but, as Kelly points out, "'initiative", "enterprise", "responsibility" or "activity" are not unproblematic characteristics of personhood' (Kelly, 2006: 30). (Though try telling that to the education policy chiefs currently charged with implementing the Curriculum for Excellence in Scotland's schools [Scottish Executive, 2004]). CfE is founded on the utopian ideal that, 'Our aspiration for all children and for every young person is that they should be successful learners, confident individuals, responsible citizens and effective contributors'. A curriculum for constructing the subjectivities required of the entrepreneurial self, that tells you not what you should know, but what you should become.

\section{Youth future?}

7.1 'Any discourse about the future has to begin with the issue of youth because young people embody the projected dreams, desires, and commitment of a society's obligations to the future' (Giroux, 2006:231). Perhaps this is why youth is currently conceived in such acutely problematic terms, the young carry the burden of a society beset with ontological uncertainties, from the credit crunch to al qaeda to global warming. A society defined by Bauman (2008) in terms of its absence - in free fall. In the face of this, 'youth' becomes the 'scapegoat generation' (Males, 1996), providing a focus for our gaze, a spectacle in the sense in which Debord (2006:7) uses it: 'not a collection of images' but 'a social relation between people that is mediated by images'. Debord (2006:7) goes on, 'The spectacle cannot be understood as a mere visual deception produced by mass-media technologies. It is a worldview that has actually been materialised, a view of a world that has become objective'. The spectacle of Wasted Youth distracts us.

7.2 So, what do we have here? A real crisis of youth or merely the perceptions of one? A felt crisis fragmented images of reality whipped up by the media to create moral panic - or a genuine breakdown in the social fabric? The answer is that this is not an 'either/or' but a 'both/and'. The problem of youth is discursively constructed within and through the discourse that produces youth as an essentialising category. The spectacle of Wasted Youth is a very real construction of unreality.

7.3 Two questions that arise from this analysis therefore are: who benefits from this discursive construction and how might the discourse be imagined differently? Clearly, there is nothing inherently, biologically 'natural' about youth as currently conceived. Nothing that could prevent the reframing of 'the problem'. But similarly, we need to recognise that the wicked problems that beset us are never amenable to 'a solution' (Rittel \& Webber, 1973). In reframing the problem there would inevitably be winners and losers, though this should not necessarily be thought of in stark terms as a zero sum game (although it might be). How can the reconfiguration of discourse be conceptualised and what could this mean in practical terms?

7.4 Young people embody our desires for the future. Desire represents the colonialisation of the future. Our desire is constructed by the hegemonic discourses waiting to meet us. In this way desire can be conceived, in Deleuze and Guattari's (2004/1972) terms, as a productive force, a power that is 'expressed as a control that extends throughout the depths of consciousnesses and bodies of the population - and at the same time across the entirety of social relations' (Hardt \& Negri, 2000:23).

7.5 Disrupting the colonialisation of the future involves re-organising the patterns of desire. One means to do this might be to create what Duncombe (2007) refers to as an ethical spectacle. The Spectacle is capital accumulated to the point that it becomes images' (Debord, 2006:17, original emphasis). What if the capital accumulated in the formation of the ethical spectacle was social and human capital (see, for example, Portes, 1998) rather than economic capital? Duncombe argues that the same imaginary techniques that consumerism uses to construct reality can be appropriated for ethical ends to promote different agendas 'transforming the techniques of spectacular capitalism into tools for social change' (Duncombe, 2007: 16). This, he argues, demands participation, 'The people who participate in the performance of the spectacle must also contribute to its construction' (Duncombe, 2007: 127):

In brief, then, a progressive ethical spectacle will be one that is directly democratic, breaks down hierarchies, fosters community, allows for diversity, and engages with reality while asking what new realities might be possible. (Duncombe, 2007:126)

7.6 Duncombe's vision, however, prompts a final scenario point: One possible world has youth accumulating social and human capital, taking control of its own image(s), creating its own spectacle. And 
what then...

Sleepshop anyone?

\section{Notes}

1 The term sounds like a Derrida-inspired neologism, but in fact comes to us from 16th century Jesuit philosopher Luis de Molina (Jouvenel, 1967:20).

2 My husband says he well remembers reading an encyclopedia as a child which said, underneath a picture of a housefly, 'Take a good look at this insect, thanks to DDT it will soon be extinct'.

3 This is brought out nicely in Bernard de Mandeville's satire The fable of the bees (1714) in which a hive of bees that in every way resembles the 'society of men'-i.e. lies, cheats, deceives etc, is made virtuous at a stroke. Peace breaks out, honesty prevails - and the hive goes into terminal decline as trade inevitably dwindles, starting with the publick houses (as the bees prefer to pay their debts rather than spend their money on drink). The moral is,

Without great vices, is a vain

Eutopia selected in the brain...

So vice is beneficial found

When it's by Justice lopt and bound

(de Mandeville 1714:19)

Mandeville concludes that the Qualifications which we all pretend to be ashamed of are the great Support of a Flourishing Society' (p.22).

4 UK Prime Minister, Gordon Brown's catchphrase - until it all went pear-shaped.

5 Tilly here makes use of the traditional narrative tactic of trebling.

${ }^{6} \mathrm{Ned}$ is a derogatory term applied to certain young people in Scotland, akin to the term chav in England. The stereotypical view of a ned is a white adolescent male, of working class background, who wears fake brand names (particularly Burberry), who engages in hooliganism, petty criminality, loutish behaviour, underage drinking and smoking or general anti-social behaviour. They are often assumed to be unemployed.' <http://en. wikipedia.org/wiki/Ned> (Scottish) [Accessed: 01.12.08]

7 Rather like the HSBC advertising campaign with the slogan 'Another point of view can sometimes open up a whole new world' (<http://www.yourpointofview.com/ page03.html> [Accessed: 14.07.09]) this binary can be overturned:
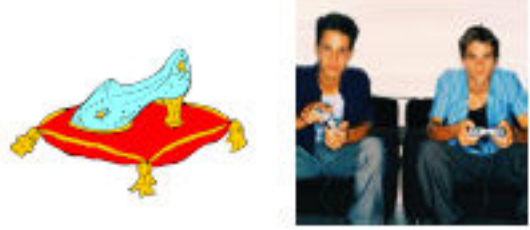

Poison
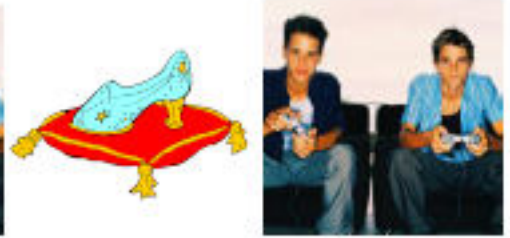

Poison
Nourishing

${ }^{8}$ Baby $\mathrm{P}$ (we now know he was called Peter) was tortured to death by his mother and her boyfriend in Haringey, South London in 2007.

${ }^{9}$ Britain locks up more children aged 10-14 than any other western European country, according to Barnardo's

${ }^{10} \mathrm{~A}$ parent/carer who receives an order will normally be required to attend counselling or guidance sessions for a period of up to three months. They may also have conditions imposed on them such as attending meetings with teachers at their child's school, ensuring their child does not visit a particular place unsupervised or ensuring their child is at home at particular times. These conditions can last for a period up to 12 months. A parent/carer can be prosecuted for failing to keep the requirements of the order. <http://www.yjb.gov.uk/engb/yjs/ SentencesOrdersandAgreements/ParentingOrder/> [Accessed: 01.12.08]

Parenting Orders have been available in England and Wales since 2000. They were introduced in Scotland in 2005, though in a parliamentary question concerning the number of PO's issued in Scotland Adam Ingram said, 'To date there have been no parenting orders granted' (10.09.08).

<http://www.scottish.parliament.uk/business/ pqa/wa-08/wa0910.htm> [Accessed: 25.11.08]

${ }^{11}$ Britain also locks up parents. The number of parents jailed for failing to stop their children playing truant 
has trebled in the past five years'. Guardian, (27.11.08) <http://www.guardian.co.uk/education/ 2008/nov/27/truancy-absent-school>

${ }^{12}$ The NEET are those Not in Education, Employment or Training. While the term is used in England, in Scotland its use has been dropped in favour of the euphemistic 'more choices more chances group'.

\section{References}

ACLAND, C.R. (1995) Youth, murder, spectacle. Boulder, Colorado: Westview Press.

AITKEN, S.C. (2001) Global crises of childhood: rights, justice and the unchildlike child. Area, Vol. 33, No. 2, pp. 119-127. [doi:10.1111/1475-4762.00015]

ALDROVANDI, U. (1610) Ornithologiae. Frankfurt.

ANDERSSON, J. (2006) Choosing futures: Alva Myrdal and the construction of Swedish Futures Studies, 1967-1972. International Review of Social History, Vol. 51, pp. 277-295. [doi:10.1017/S0020859006002458]

ARMSTRONG, D. (2004) A Risky Business? Research, Policy, Governmentality and Youth Offending. Youth Justice, Vol. 4, No.2, pp. 100. [doi:10.1177/147322540400400203]

BARNARDO'S (2008) Breaking the cycle. Believe in children. Ilford, Essex: Barnardo's.

BAUMAN, Z. (2008) The absence of society. The Social Evils Series. York: Joseph Rowntree Foundation.

BECKER, H. (2003) Outsiders. In: E. McLaughlin, J. Muncie and G. Hughes, (editors) Criminological perspectives: essential readings. $2^{\text {nd }}$ edition. London: Sage.

BOOTH, C., ROWLINSON, M., CLARK, P., DELAHAYE, A. and PROCTER, S. (2008) Scenarios and counterfactuals as modal narratives. Futures, doi:10.1016/j.futures.2008.07.037.

DE CERTEAU, M. (1988) The practice of everyday life. Berkely and Los Angeles. London: University of California Press.

DEBORD, G. (2006) Society of the spectacle. London: Rebel Press.

$<$ http://www.bopsecrets.org/SI/debord/>

DELEUZE, G. (1995) Negotiations. New York: Columbia University Press.

DELEUZE, G. and GUATTARI, F. (2004 [1972]) Anti-oedipus. Capitalism and schizophrenia. London: Athlone Press.

DOLEŽEL, L. (1998) Heterocosmica. Fiction and possible worlds. Baltimore and London: The John Hopkins University Press.

DUNCOMBE, S. (2007) Re-imagining progressive politics in an age of fantasy. London: The New Press.

EHLIASSON, K. (2007) Futures studies as social science: An analytic scheme and a case study. Futures Vol. 40, pp.489-502 [doi:10.1016/j.futures.2007.10.007]

FARRINGTON, D. (1996) Understanding and preventing youth crime. Social Policy Research 93. York: Joseph Rowntree Foundation.

GIDLEY, J. (2005) Giving hope back to our young people: Creating a new spiritual mythology for Western culture. Journal of Futures Studies, Vol. 9, No.3, pp. 17-30.

GIROUX, H. (2006) America on the Edge : Henry Giroux on Politics, Culture, and Education. Gordonsville, VA, USA: Palgrave Macmillan.

GOLDING, W. (1954) Lord of the Flies. London: Faber and Faber.

HARDT, M. and NEGRI, A. (2000) Empire. Cambridge, Mass.: Harvard University Press.

HERZ, J.H. (1966) Review of History and futurology, by Ossip K. Flechtheim. The American Political Science Review, Vol. 60, No. 4, pp. 1019-1020.

HUXLEY, A. (2004[1932]) Brave New World. London: Vintage.

INAYATULLAH, S. (2004) Causal layered analysis: theory, historical context, and case studies. In: S. Inayatullah, (editor), The causal layered analysis (CLA) reader. Theory and case studies of an integrative and transformative methodology. Taiwan: Tamkang University Press, pp. 8-49.

<http://www.metafuture.org/Books/causal_layered_analysis_reader.htm>

INAYATULLAH, S. (1998b) Macrohistory and futures studies. Futures, Vol. 30, pp. 381-394.

[doi:10.1016/S0016-3287(98)00043-3]

INAYATULLAH, S. (1998a) Causal layered analysis Poststructuralism as method. Futures, Vol. 30, pp. 
JEFFS, T. and SMITH, M.K. (1999) The Problem of' Youth for Youth Work. Youth and Policy, Vol. 62, pp. 45-66.

JOUVENEL, B.D. (1967) The art of conjecture. London: Weidenfeld and Nicolson.

KATZ, C. (2008) Cultural Geographies lecture: Childhood as spectacle: relays of anxiety and the reconfiguration of the child. Cultural Geographies, Vol. 15, No.1, pp. 5-17. [doi:10.1177/1474474007085773]

KELLY, P. (2006) The Entrepreneurial Self and 'Youth at-risk': Exploring the Horizons of Identity in the Twenty-first Century. Journal of Youth Studies, Vol. 9, No. 1, pp. 17-32. [doi:10.1080/13676260500523606]

KING, M. (2007) The Sociology of Childhood as Scientific Communication: Observations from a social systems perspective. Childhood, Vol. 14, No. 2, pp. 193. [doi:10.1177/0907568207078327]

LACLAU, E. and MOUFFE, C. (1985) Hegemony and socialist strategy. London: Verso.

MAIRA, S. and SOEP, E. (2004) United States of Adolescence?: Reconsidering US Youth Culture Studies. Young, Vol. 12, No. 3, pp. 245. [doi:10.1177/1103308804044508]

MALES, M. (1999)Scapegoat generation: America's war on adolescents. Monroe, ME: Common Courage Press.

MANDEVILLE, B.D. (1714)The fable of the bees. Or, private vices, publick benefits. London: J. Roberts.

MCQUILLAN, M. (editor) (2000) The Narrative Reader. London and New York: Routledge.

MILESTONE, J. (2007) Design as Power: Paul Virilio and the Governmentality of Design Expertise.

Culture, Theory and Critique, Vol. 48, No. 2, pp. 175-198. [doi:10.1080/14735780701723264]

MORROW, R. (2007) What is the Debate around Paid Maternity Leave Really about? Using CLA to Delve under the Surface... Journal of Futures Studies, Vol. 11, No. 4, pp. 59-76.

NOLAN, W.F. and CLAYTON JOHNSON, G. (1967) Logan's run. USA: Dial Press.

PHELAN, J. (2006) Rhetorical aesthetics and other issues in the study of literary narrative. Narrative Inquiry, Vol. 16, No.1, pp. 85-93. [doi:10.1075/ni.16.1.12phe]

POLAK, F. (1961) The image of the future. Volume II. New York: Oceana Publications.

PORTES, A. (1998) SOCIAL CAPITAL: Its Origins and Applications in Modern Sociology. Annual Reviews in Sociology, Vol. 24, No.1, pp. 1-24. [doi:10.1146/annurev.soc.24.1.1]

PRYOR, J. (2006) Beyond demography: history, ritual and families in the twenty-first century. Blue Skies Report 7/06 edn. New Zealand: Families Commission.

RITTEL, H.W.J. and WEBBER, M.M. (1973) Dilemmas in a general theory of planning. Policy Sciences, Vol. 4, No. 2, pp. 155-169. [doi:10.1007/BF01405730]

SCOTTISH EXECUTIVE (2004) A Curriculum for Excellence. Edinburgh: Scottish Executive.

STEPHENSON, S. (2001) Street children in Moscow: using and creating social capital. The Sociological review, Vol. 4, No.4, pp. 530-547. [doi:10.1111/1467-954X.00346]

THRAKE, S. (2008) Individualism and consumerism: reframing the debate. The Social Evils Series. York: Joseph Rowntree Foundation.

TILLY, C. (1999) The trouble with stories. The social worlds of Higher Education.

$<$ http://www. pineforge.com/ textbooksProdDesc.nav?prodld=Book9153\&currTree=Subjects\&level $1=$ No0\&level2=NE0\&level3=NE2>

Handbook for Teaching in a New Century. B. Pescosolido \& R. Aminzade (Eds) Thousand Oaks: Pine Forge Press, pp. 256-270.

TILLY, C. (1990) How (and What) Are Historians Doing? American Behavioral Scientist, Vol. 33, No.6, pp. 685. [doi:10.1177/0002764290033006005]

TORFING, J. (1999) New Theories of Discourse: Laclau, Mouffe and Zizek. Oxford: Blackwell.

VADIM, R. (1968) Barbarella. USA: Paramount.

VIRILIO, P. (2007) The original accident. Cambridge: Polity Press.

WALTERS, R. and WOODWARD, R. (2007) Punishing 'Poor Parents': 'Respect', 'Responsibility' and Parenting Orders in Scotland. Youth Justice, Vol. 7, No. 1, pp. 5-20 [doi:10.1177/1473225406074818]

WALTON, J.S. (2008) Scanning Beyond the Horizon: Exploring the Ontological and Epistemological Basis 
for Scenario Planning. Advances in Developing Human Resources, Vol. 10, No.2, pp. 147-165 [doi:10.1177/1523422307304101]

WATSON, C. (2008) Reflexive research and the (re)turn to the baroque. (Or how I learned to stop worrying and love the university). Rotterdam: Sense <https://www.sensepublishers.com/ product_info.php? cPath=\&products_id= 644\&osCsid=1a7> 